\title{
From Injection Molding to 3d Printing of Patient-Specific Implants
}

\author{
Maureen van Eijnatten ${ }^{1 *}$, Dafydd Visscher ${ }^{2}$, Jac Koenen ${ }^{3}$ and Jan Wolff ${ }^{4}$ \\ ${ }^{1}$ Department of Oral and Maxillofacial Surgery/Pathology - 3D Innovation Lab \& Centrum Wiskunde \& Informatica, Amsterdam UMC, Vrije Universiteit \\ Amsterdam, The Netherlands \\ ${ }^{2}$ Department of Plastic, Reconstructive \& Hand Surgery, Amsterdam Movement Sciences, Amsterdam UMC, Vrije Universiteit Amsterdam, the Netherlands \\ ${ }^{3}$ DSM Biomedical Materials B.V. Geleen, The Netherlands \\ ${ }^{4}$ Department of Oral and Maxillofacial Surgery/Pathology - 3D Innovation Lab, Amsterdam UMC, Vrije Universiteit Amsterdam, The Netherlands
}

Received: 盋 August 25, 2018; Published: 阱 August 29, 2018

*Corresponding author: Maureen van Eijnatten, Amsterdam UMC, Vrije Universiteit Amsterdam, Department of Oral and Maxillofacial Surgery/Pathology - 3D Innovation Lab, Amsterdam Movement Sciences, De Boelelaan 1117, Amsterdam, The Netherlands \& Centrum Wiskunde \& Informatica P.0. Box 94079, 1090 GB Amsterdam, The Netherlands

Keywords: 3D Printing; Medical; Polymer; Implant

Abbreviations: GDP: Gross Domestic Product; PEEK: Poly-Ether Ether Ketone; SLS: Selective Laser Sintering; FDA: Food and Drug Administration

\section{Editorial}

The number of patients suffering from damaged or diseased tissues has increased due to an aging population. The result has been a greater socioeconomic burden on society. For example, the United States alone spends $17.1 \%$ of its gross domestic product (GDP) on health care [1,2]. Hence, there is a pressing need to develop novel cost-effective methods for tissue reconstruction using medical grade implants. Historically, such implants have been manufactured using traditional manufacturing technologies such as injection molding. Unfortunately, these technologies have certain drawbacks, namely they are often reserved for mass production due to the high initial costs involved and part design restrictions. Moreover, medical implants are often produced in generic sizes that are commonly based on an "average" patient. One solution to these problems is to manufacture patient-specific implants using 3D printing. This allows precise control of size, shape and geometry of the implant to better mimic native tissues $[3,4]$. Compared to traditional manufacturing, however, the 3D printing of medical implants is still in its infancy. Pro tempore, titanium alloys and polyether ether ketone (PEEK) implants are sporadically manufactured using selective laser sintering (SLS) printing technologies $[5,6]$. However, both titanium and PEEK have certain drawbacks.

For example, they both require high printing temperatures above $300^{\circ} \mathrm{C}$, and therefore such implants are more expensive to manufacture. Furthermore, such materials are difficult to sculpture during surgery due to their rigidity (>120 GPa) [7]. Hence, novel printable, implant-grade materials are still sought. Polymers have several advantages over titanium. These include lower cost, reduced weight, and excellent biocompatibility [8]. Furthermore, there are a plethora of possibilities for tailoring the material, processing, and product properties of polymers [9]. However, the lack of printable polymers suitable for medical applications still remains $[5,10]$. Very few printable polymers currently comply with American Food and Drug Administration (FDA) and European medical device regulations. Fortunately, the FDA $510(\mathrm{k})$ clearance process allows changes to be made to the manufacturing processes of existing polymers that have initially been developed for traditional manufacturing technologies such as injection molding [11]. As a consequence, the FDA approval time required to change the manufacturing process of an existing implant- grade polymer from injection molding to 3D printing can be markedly shortened. However, printing medical constructs that have qualities comparable to those acquired during injection molding remains a challenge $[12,13]$.

In 3D printing, the print properties and quality largely depend on the material flow behavior, which can be characterized by the viscosity function using rheology. The viscosity function of a polymer is known to be influenced by extrusion temperature, flow rate, molecular weight, and chain structure. In this context, it must be noted that polymers will not be able to flow or take shape if the extrusion pressure and temperature are too low but can also degrade if the temperature is too high. Therefore, the operation window has to be carefully chosen and adjusted accordingly. 
However, flow instabilities such as melt fracture or surface distortions may arise within or outside the printer extruder setup, e.g., in cases of high processing rates or internal stresses. Another challenge that remains in the 3D printing of polymers are the temperature differences between the adjacent layers in the build. These differences in temperatures mean that cooling occurs when the heated nozzle moves from one build area to another. Uneven cooling can lead to a reduction in mechanical properties such as the tensile strength of the printed construct, particularly in the Z-direction of the build [14-16]. This problem could be solved by properly re-heating the previously printed layer, and thus allowing the large polymer chains to diffuse across the layer interface. The diffusion speed (D) of the polymer chains is inversely related to the molecular weight, $\mathrm{M}_{w^{\prime}}$ of the polymer chains $\left(D \propto 1 /\left(M_{w}\right)^{3}\right.$ also strongly dependent on the melt temperature $\left(D \propto T_{2}\right)$ [17].

Therefore, layer adhesion can be improved by lowering the molecular weight and raising the melt temperature of polymers. Another option is to enhance the interfacial strength by applying adhesive possibilities that "glue" the layer interfaces by means of reactive chemistry. An even more advanced option would be to use photopolymers, which offer better intrinsic adhesion between successive layers. However, to the best of our knowledge no ISO10993 implant-grade photopolymers are currently available on the market. In conclusion, 3D printing of patient-specific implants using existing FDA-approved polymers is feasible. However, achieving the corresponding physical, structural and mechanical properties of injection-molded constructs still remains a challenge. Future research should focus on optimizing both the material and processing parameters of polymers and developing novel (photo) polymers for $3 \mathrm{D}$ printing.

\section{References}

1. Christopher JL Murray, Theo Vos, Rafael Lozano, Zhi-Jie Zheng, David Zonies, et al. (2012) Disability-adjusted life years (DALYs) for 291 diseases and injuries in 21 regions, 1990-2010: a systematic analysis for the Global Burden of Disease Study 2010. Lancet 380(9859): 21972223.

2. (2013) World Health Organization: Global Health Expenditure database, 2013.

\section{ISSN: 2574-1241}

DOI: $10.26717 / B J S T R .2018 .08 .001660$

Maureen van Eijnatten. Biomed J Sci \& Tech Res

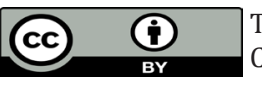

This work is licensed under Creative Commons Attribution 4.0 License

Submission Link: https://biomedres.us/submit-manuscript.php
3. Choonara YE, du Toit LC, Kumar P, Kondiah PPD, Pillay V (2016) 3D-printing and the effect on medical costs: a new era? Expert Rev Pharmacoecon Outcomes Res 16(1): 23-32.

4. Visscher DO, Farré Guasch E, Helder MN, Gibbs S, Forouzanfar T, et al. (2016) Advances in Bioprinting Technologies for Craniofacial Reconstruction. Trends Biotechnol 34(9): 700-710.

5. Schmidt M, Pohle D, Rechtenwald T (2007) Selective Laser Sintering of PEEK. CIRP Ann - Manuf Technol 56(1): 205-208.

6. Rotaru H, Schumacher R, Kim SG, Dinu C (2015) Selective laser melted titanium implants: a new technique for the reconstruction of extensive zygomatic complex defects. Maxillofac Plast Reconstr Surg 37(1): 1.

7. Schuh A, Bigoney J, Hönle W, Zeiler G, Holzwarth U, Forst R (2007) Second generation (low modulus) titanium alloys in total hip arthroplasty. Materwiss Werksttech 38(12): 1003-1007.

8. Maitz MF (2015) Applications of synthetic polymers in clinical medicine. Biosurface and Biotribology 1(3): 161-176.

9. Lendlein A (2010) Polymers in Biomedicine. Macromol Biosci 10(9): 993-997.

10. Woodruff MA, Hutmacher DW (2010) The return of a forgotten polymerPolycaprolactone in the $21^{\text {st }}$ century. Prog Polym Sci 35(10): 1217-1256.

11. FDA. Section 510(k) of the Food, Drug and Cosmetic Act 2016.

12. Wendel B, Rietzel D, Kühnlein F, Feulner R, Hülder G, Schmachtenberg E (2008) Additive Processing of Polymers. Macromol Mater Eng 293(10): 799-809.

13. Caulfield B, McHugh PE, Lohfeld S (2007) Dependence of mechanical properties of polyamide components on build parameters in the SLS process. J Mater Process Technol 182(1-3): 477-488.

14. Kim GD, Oh YT (2008) A benchmark study on rapid prototyping processes and machines: Quantitative comparisons of mechanical properties, accuracy, roughness, speed, and material cost. Proc Inst Mech Eng Part B J Eng Manuf 222(2): 201-215.

15. Ahn S, Montero M, Odell D, Roundy S, Wright PK (2002) Anisotropic material properties of fused deposition modeling ABS. Rapid Prototyp J 8(4): 248-257.

16. Lee CS, Kim SG, Kim HJ, Ahn SH (2007) Measurement of anisotropic compressive strength of rapid prototyping parts. J Mater Process Technol 187(188): 627-630.

17. Kim S G, Suh NP (1986) Performance prediction of weldline structure in amorphous polymers. Polym Eng Sci 26(17): 1200-1207.

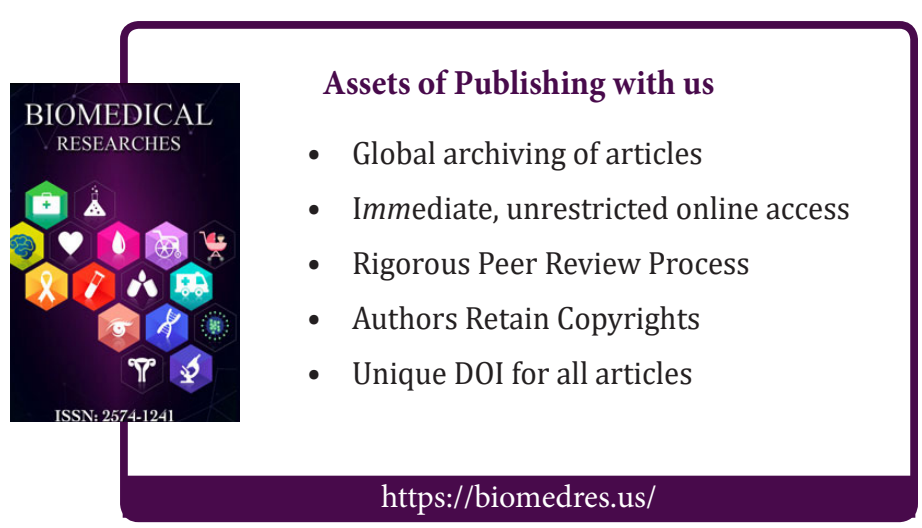

